\title{
Supplementary Data
}

Title: The Incorporation of a New-type Transition Metal Complex into Thioarsenate Anion: Syntheses, Structures and Properties of Two Novel Compounds $\left[\mathrm{Mn}_{3}(2,2 \text { '-bipy })_{3}\left(\mathrm{As}^{\mathrm{V}} \mathrm{S}_{4}\right)_{2}\right]_{\mathrm{n}} \cdot \mathrm{nH}_{2} \mathrm{O}$ and $\mathrm{Mn}_{2}\left(2,2^{\prime}\right.$ '-bipy $) \mathrm{As}_{2}{ }^{\mathrm{III}} \mathrm{S}_{5}$

Authors: Ming-Lai Fu, Guo-Cong Guo, Xi Liu, Wen-Tong Chen, Bing Liu, Jin-Shun Huang

\section{Part I Infrared Spectra of 1 and 2.}

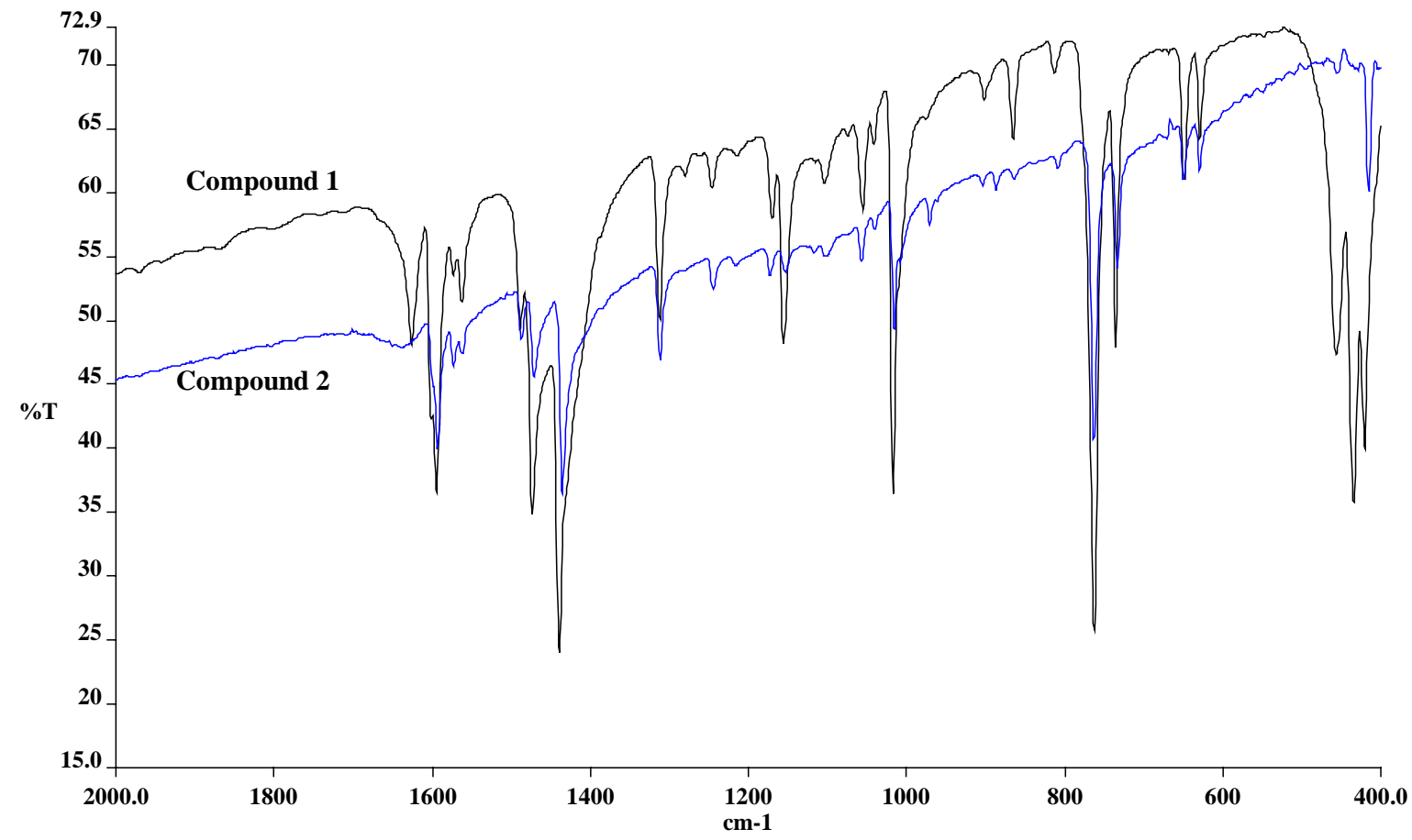

\section{Part II The structural diagrams.}




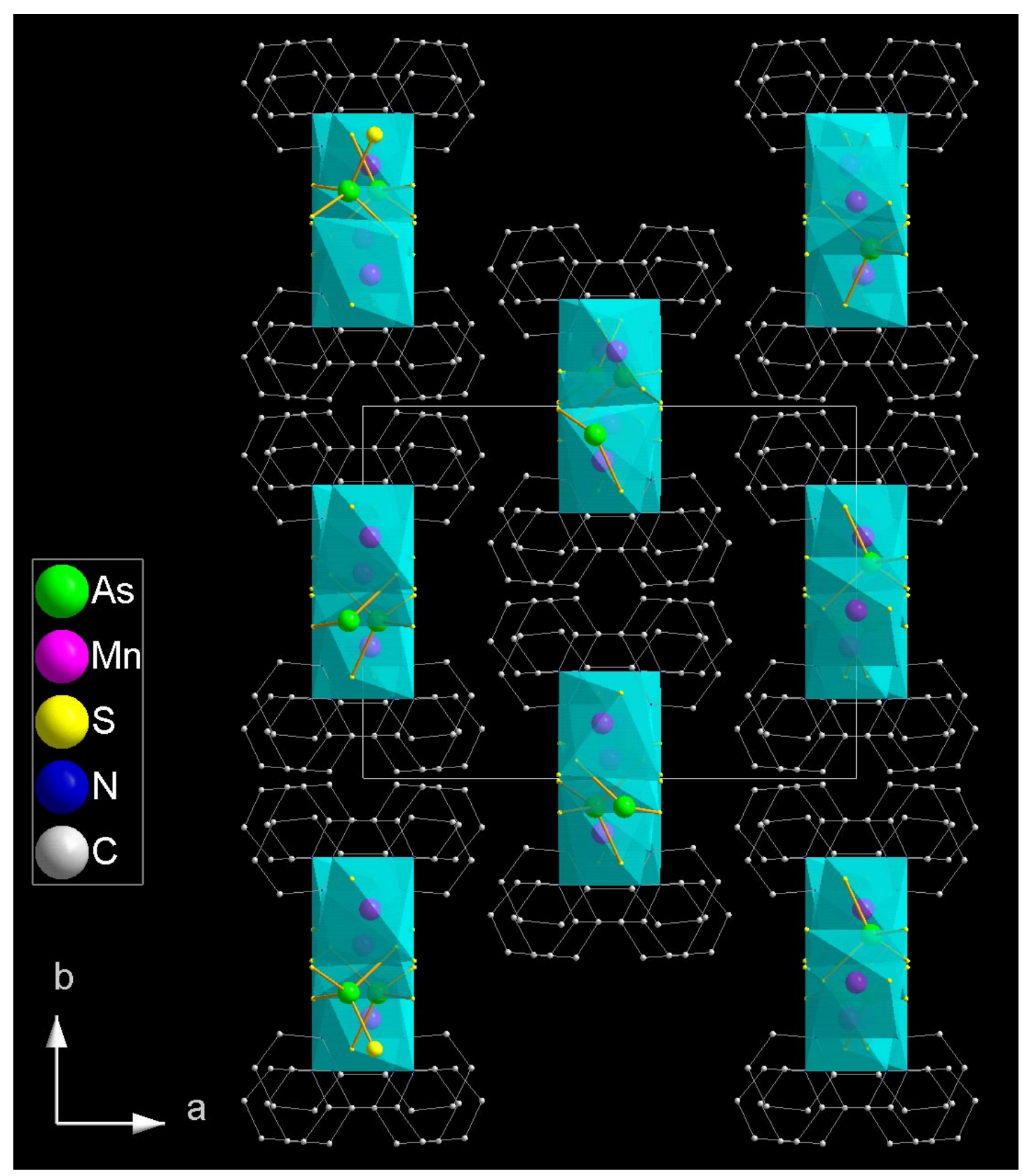

Figure S1. The pack diagram of $\mathbf{1}$ viewed along the $c$ direction. Water molecules are omitted for clarity.

Part III DTA and TG curves for 1 and 2: 


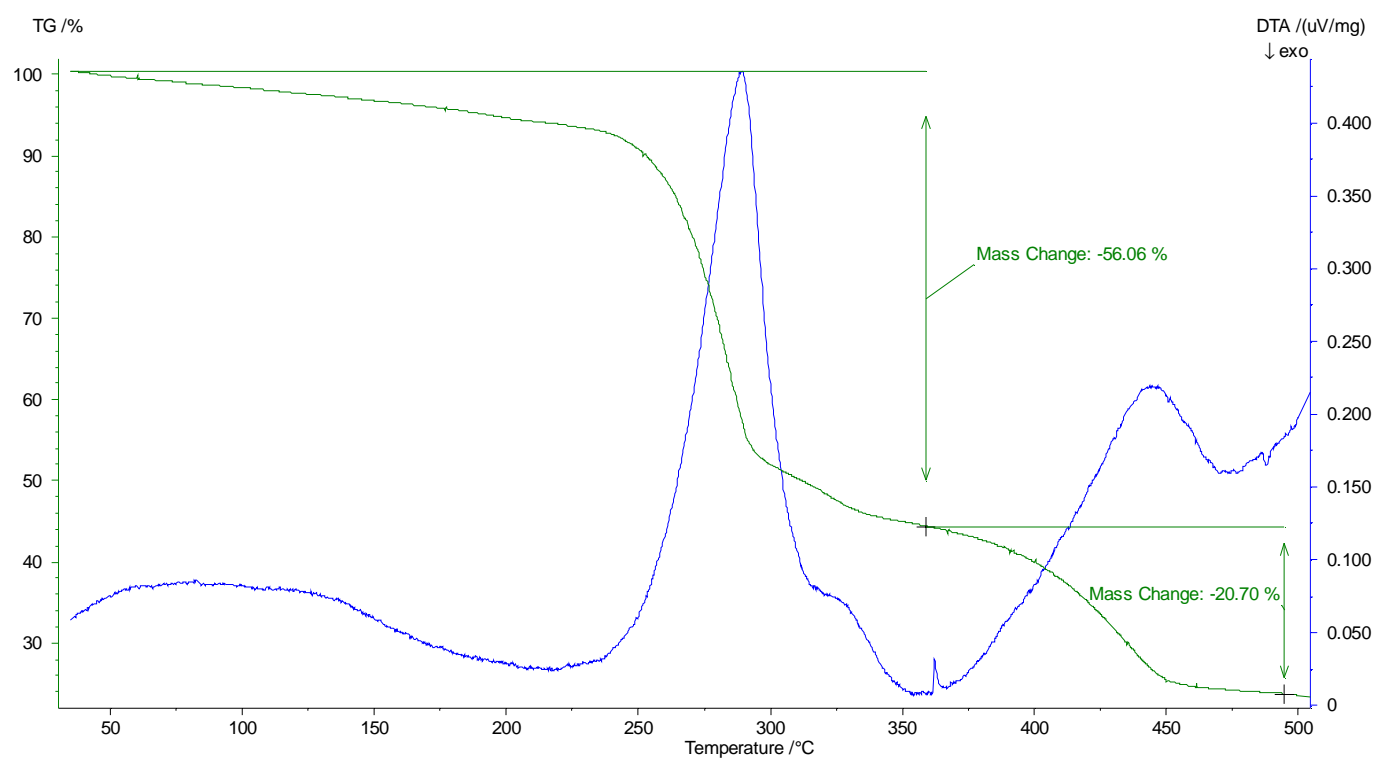

Figure S2. DTA and TG curves for $\mathbf{1}$

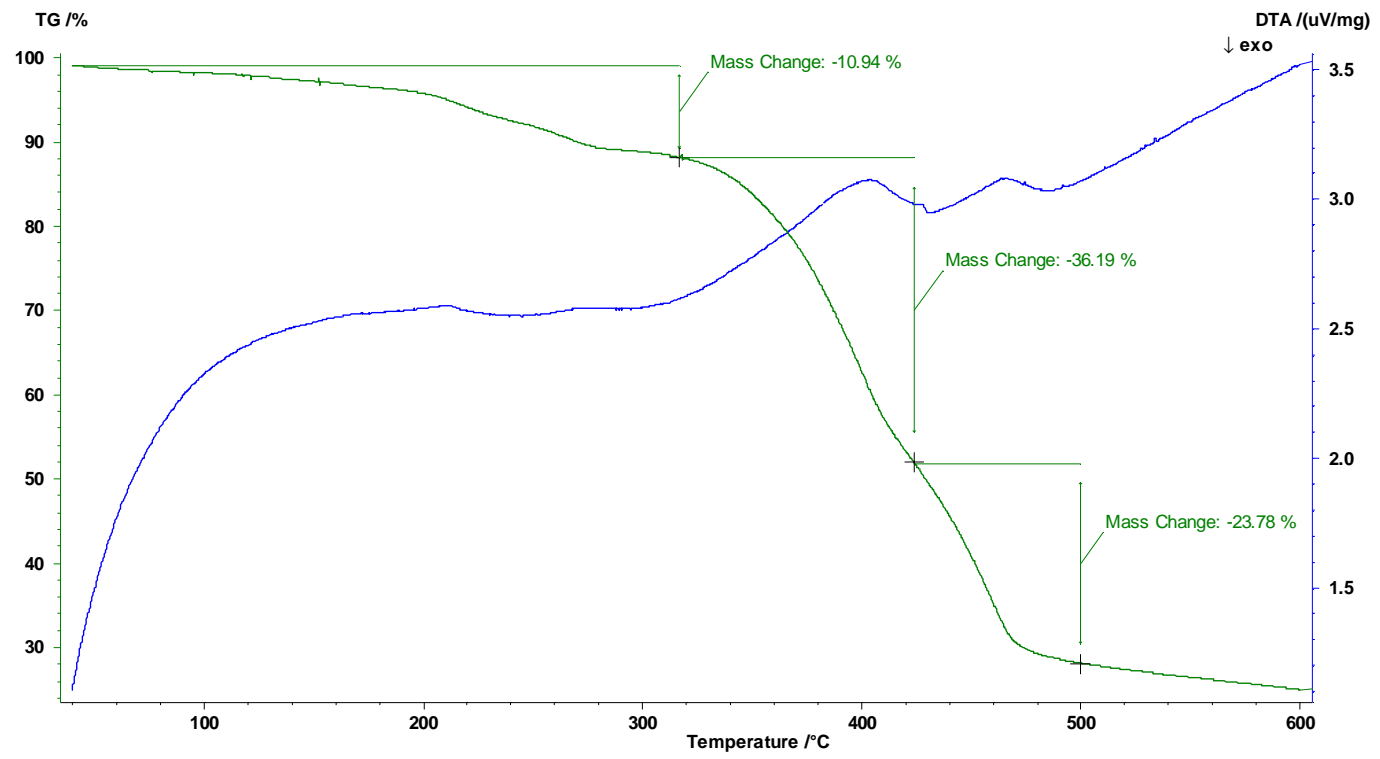

Figure S3. DTA and TG curves for 2.

Part IV Solid-state photoluminescent spectra of two compounds. 


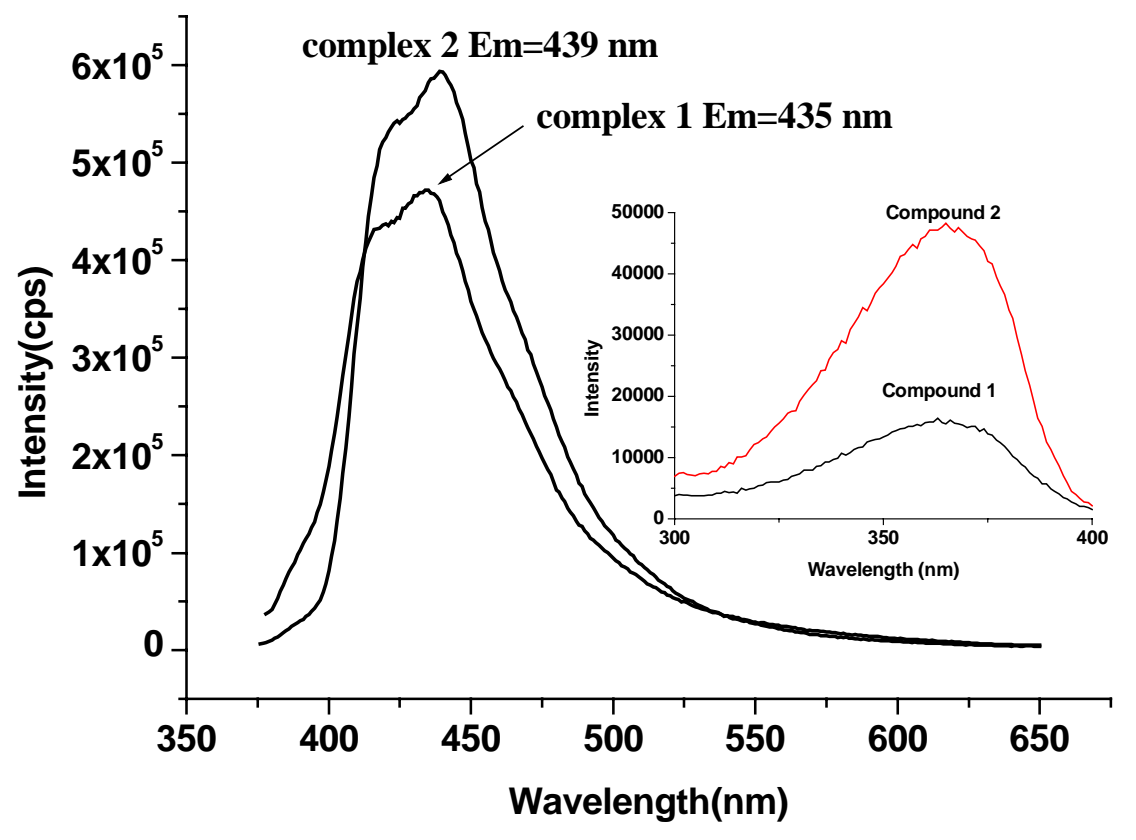

Figure S4. Solid-state photoluminescent spectra of $\mathbf{1}$ and $\mathbf{2}$ at room temperature (365 nm excitation). Inset: Excitation spectra of $\mathbf{1}$ (black) and $\mathbf{2}$ (red) in the solid state.

Part V Optical absorption spectra of two compounds. 


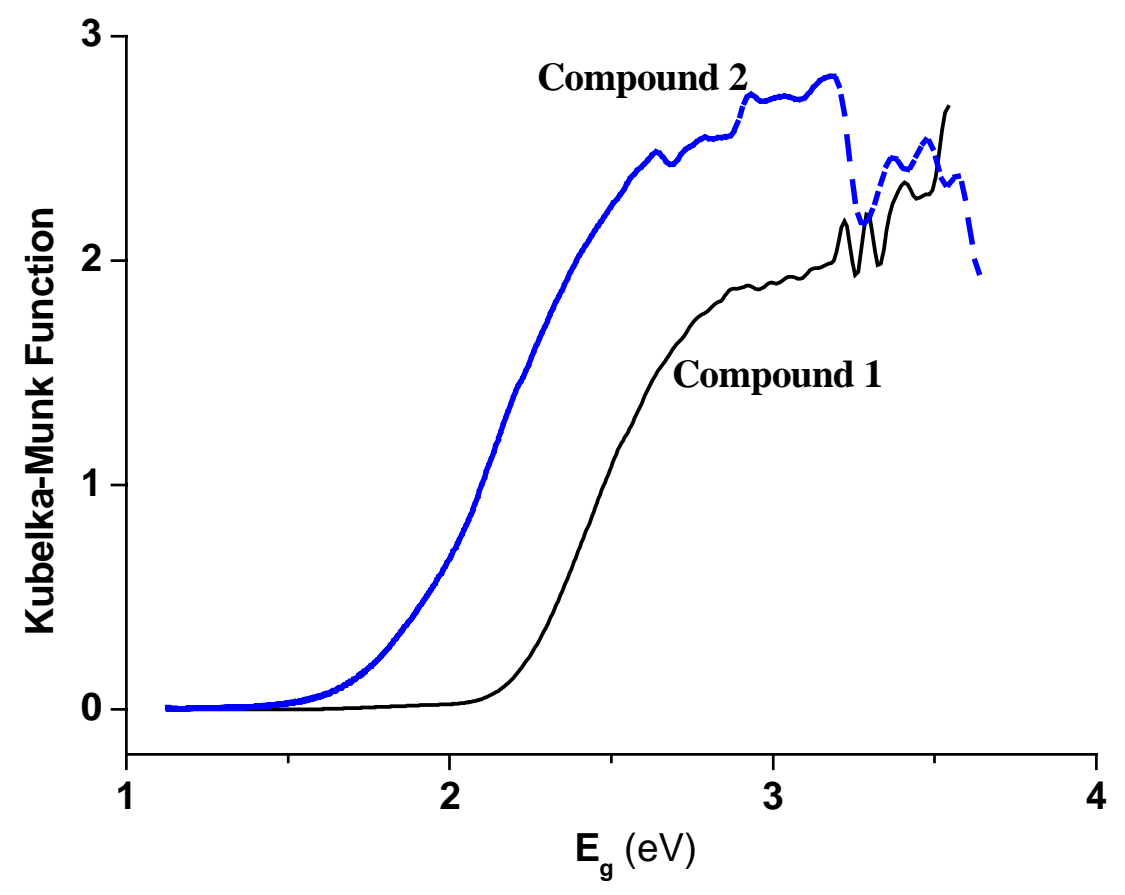

Figure S5. Optical absorption spectra of two compounds.

Part VI Experimental and simulated powder X-ray diffraction patterns of two compounds. 


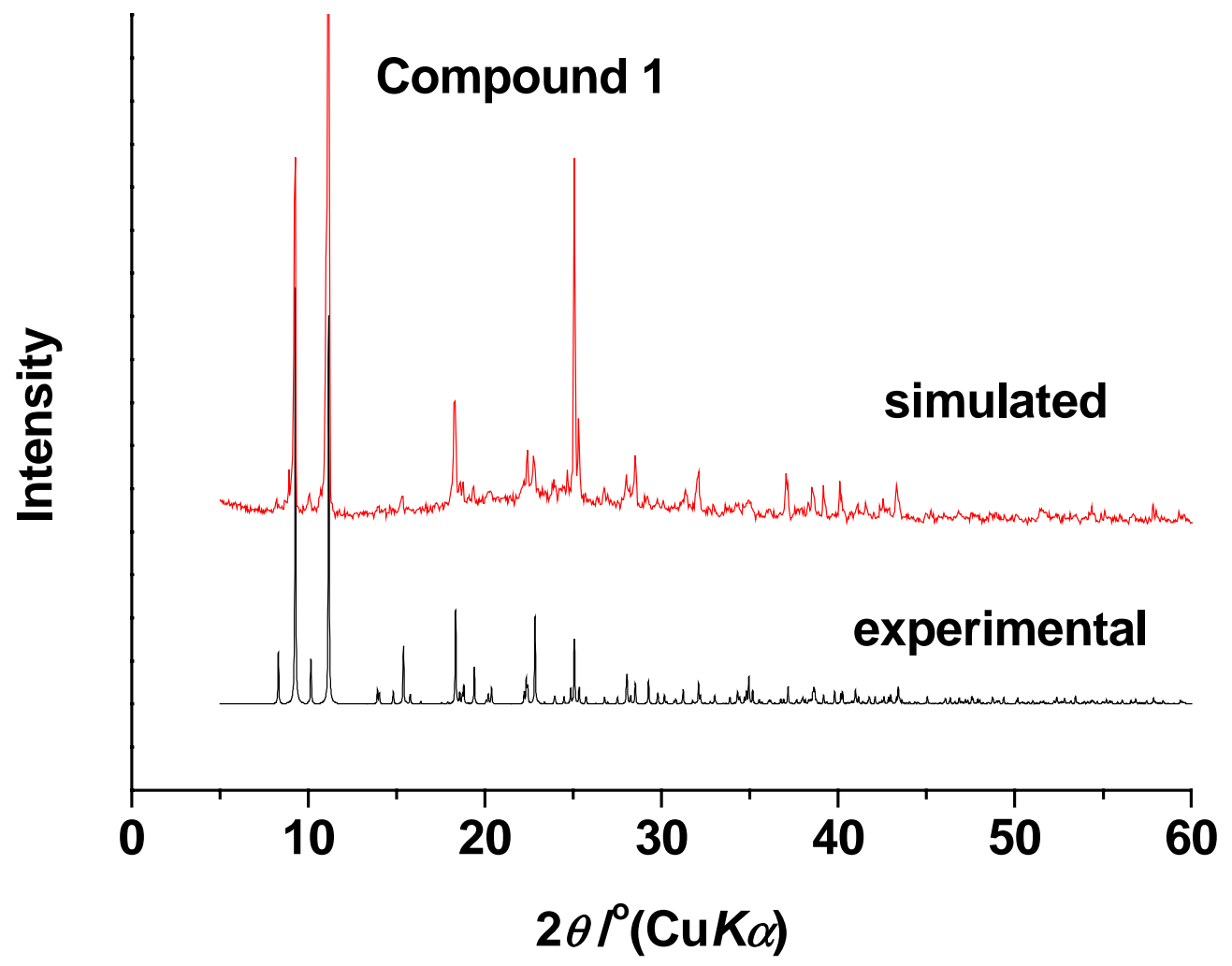

(a) 


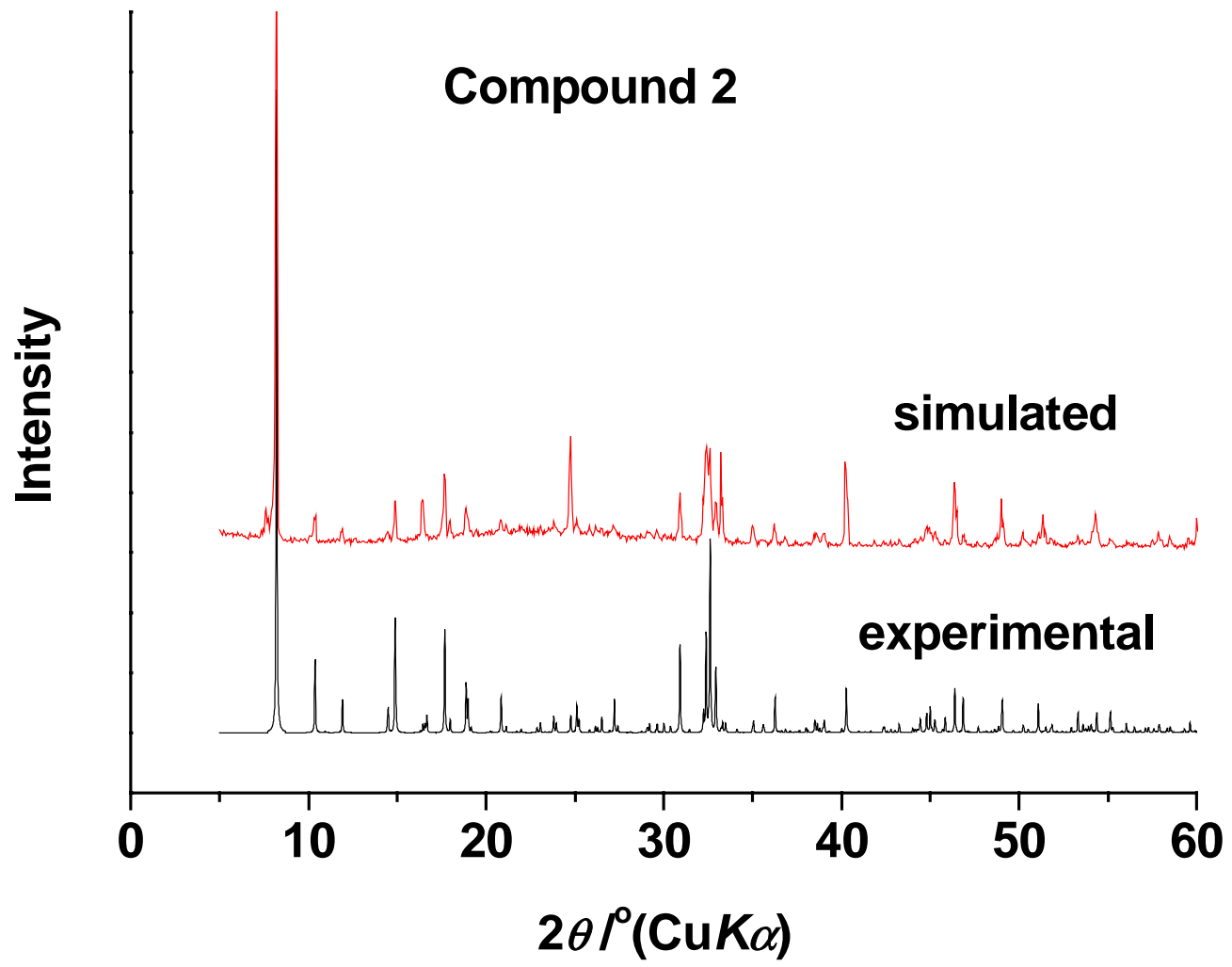

(b)

Figure S6. Experimental and simulated powder X-ray diffraction patterns of two compounds.

Part VII $\chi_{M}{ }^{-1}$ of $1\left(M_{3}\right)$ and $2\left(M_{2}\right)$ versus $T$ plots for 1 and 2 . The solid lines represent the best fit of the experimental data of the Curie-Weiss law. 


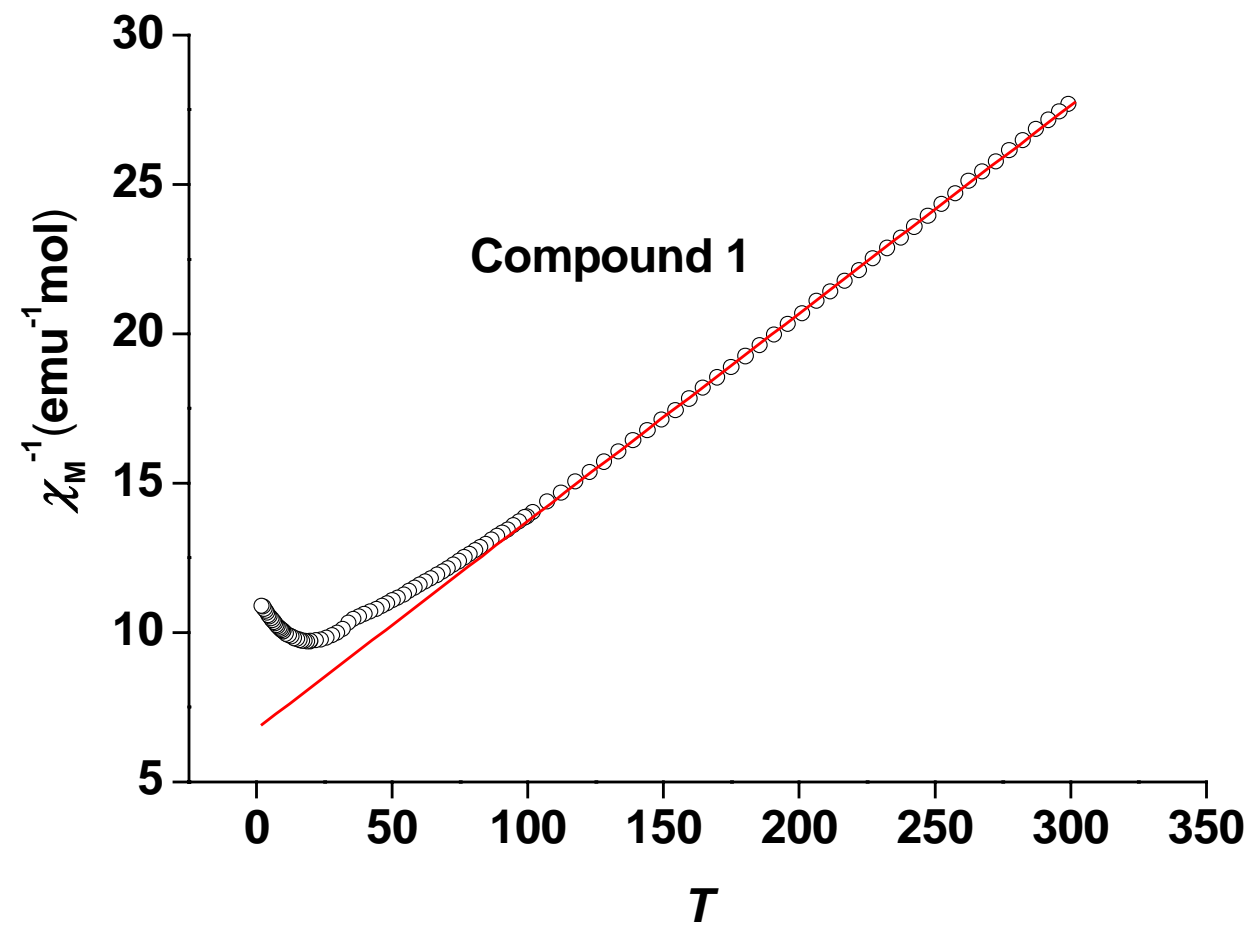

(a) 


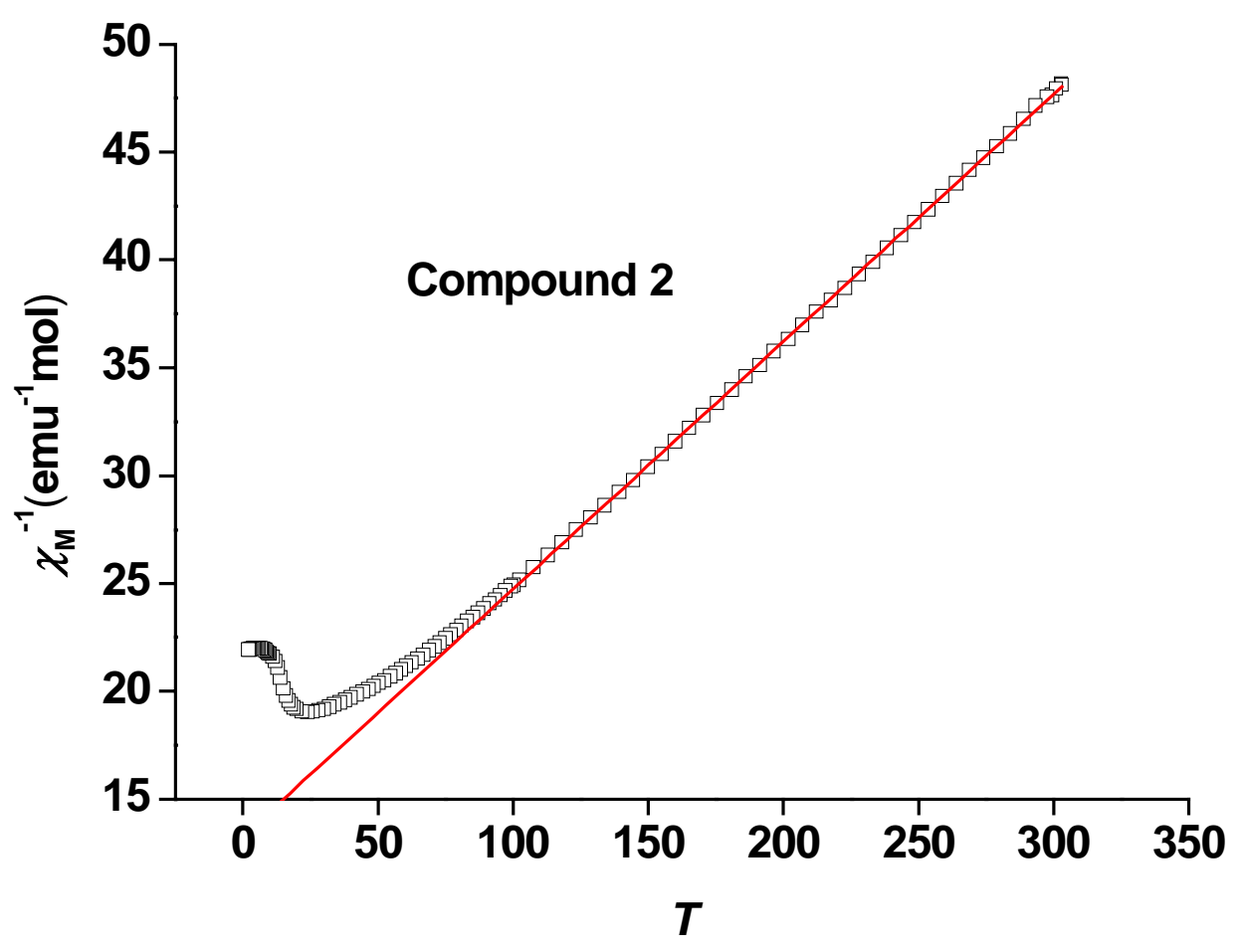

(b)

Figure S7. $\chi_{M}{ }^{-1}$ of $1\left(\mathrm{Mn}_{3}\right)$ and $2\left(\mathrm{Mn}_{2}\right)$ versus $T$ plots for $\mathbf{1}$ and $\mathbf{2}$. The solid lines represent the best fit of the experimental data of the Curie-Weiss law.

Part VIII The field dependent magnetization of two compounds at 2 K 


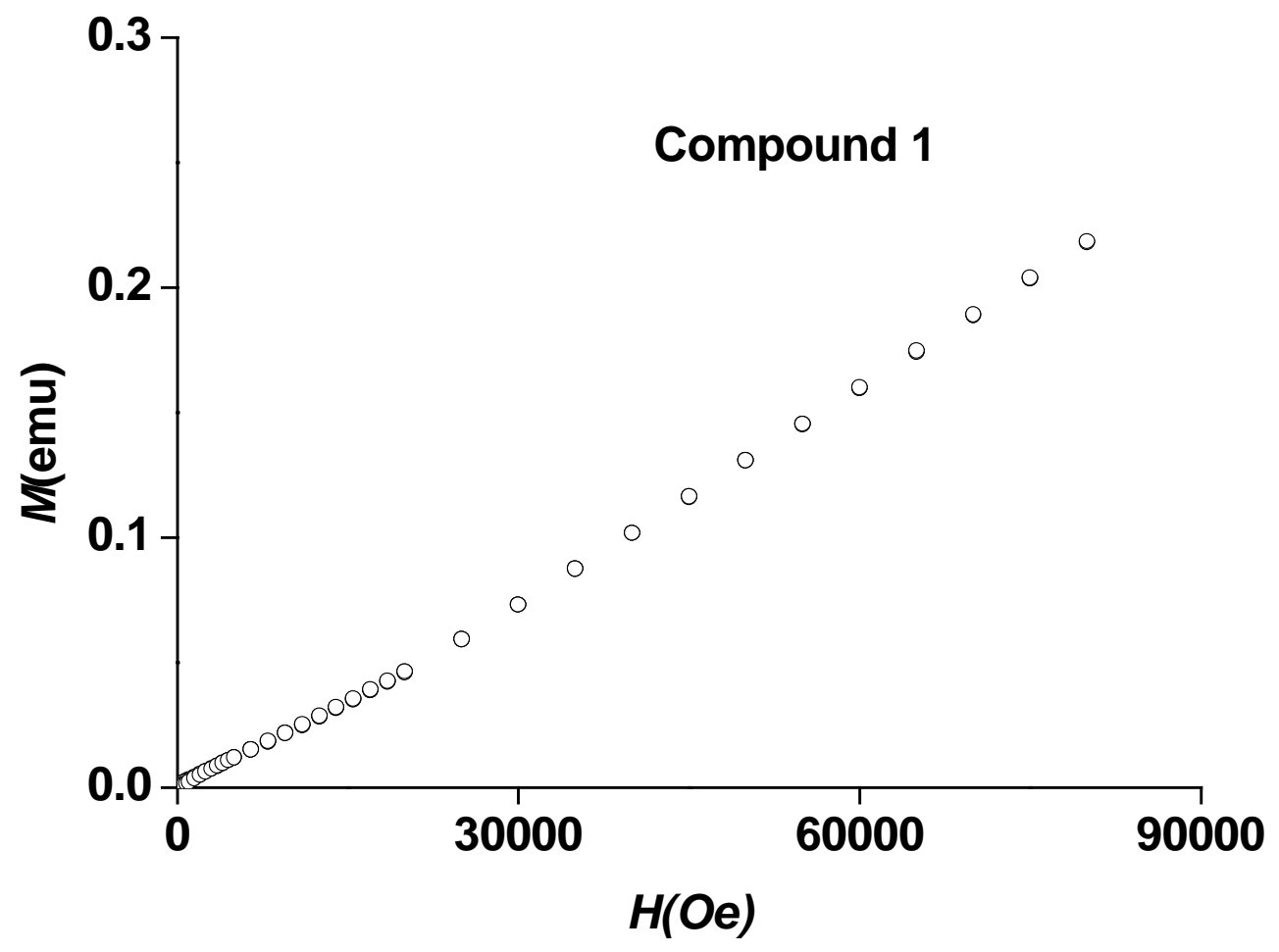

(a) 


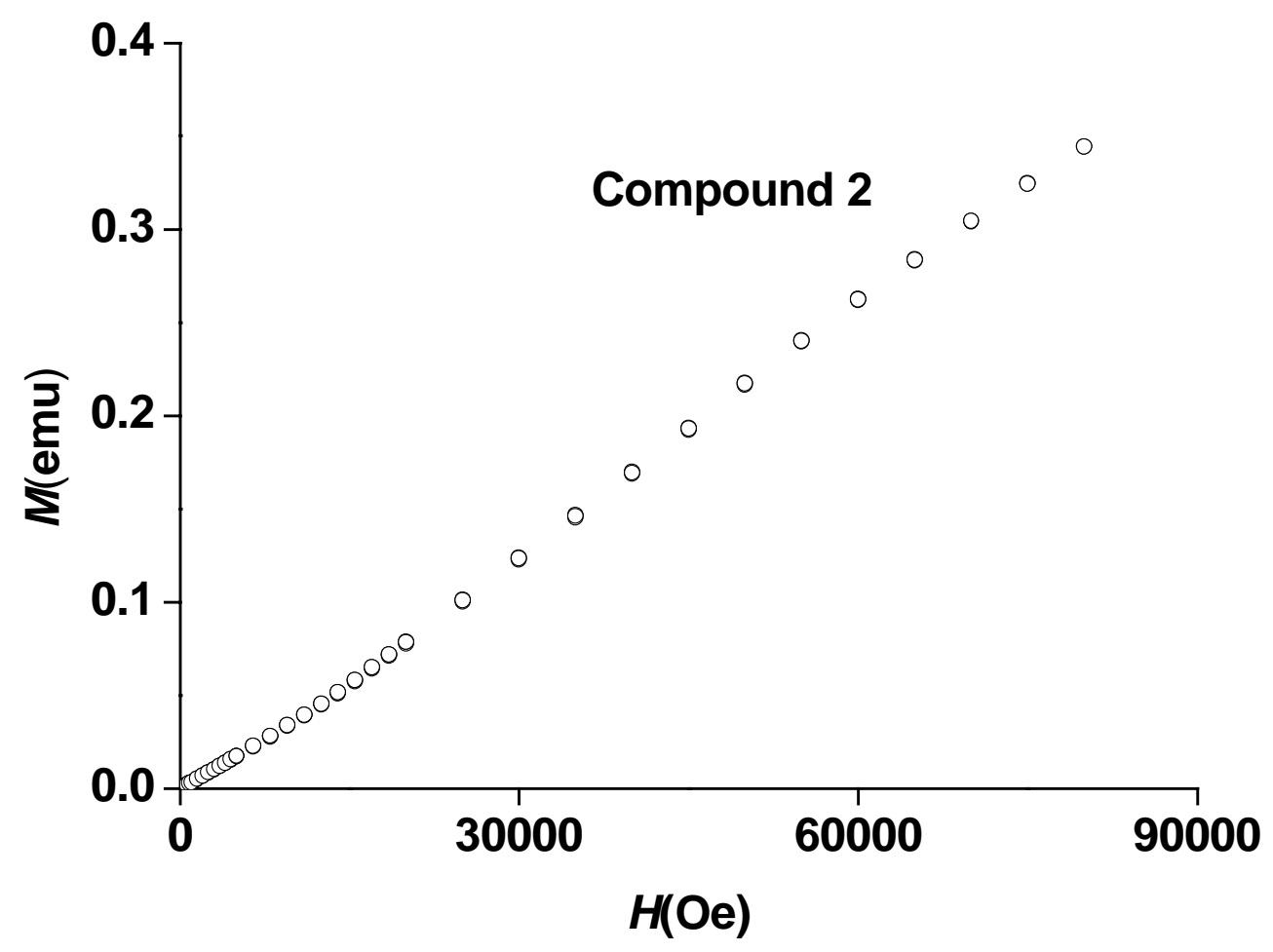

(b)

Figure S8. The field dependent magnetization of two compounds at $2 \mathrm{~K}$. 